\title{
The School Library as a Bridge to Literacy: A Garden of Words
}

\author{
Yvonne Perriel \\ Principal of Goshen All Age, \\ St. Elizabeth, \\ Jamaica \\ Y perriel@yahoo.com
}

\begin{abstract}
Administrators and teachers have the expertise to utilize theoretical and practical experiences in dealing with students but are unaware of the vital role of parental involvement in students' academic achievement. The purpose of this research was to explore whether the impact of the implementation of a literacy garden could improve reading level of fourth grade boys at Northside All Age School. Data was obtained using the quasi experimental design. Fifty-three students from two classes grade four at Northside All Age were used. The study was done after a survey was conducted among children in grade four. Data were analyzed using charts and descriptive statistics. . Some of the findings revealed that the implementation of literacy garden has a positive effect of literacy at grade four. The reading level of the boys increases as their self-esteem increases. It was recommended, based on the findings that parents should be more involved in their child's life at school. That both teachers and parents should motivate slow readers and also that teachers use teaching strategies that will help children who are slow readers
\end{abstract}

Keywords: School libraries, Literacy, Parents' involvement, Boys, Reading

\section{Introduction}

Excellence or any level of success on the part of students depends heavily on parental involvement. Jesse (1997) confirmed that parental involvement in education significantly "increases students' achievement and also creates a positive school environment." Fullan (2004) also asserted that "parental involvement is a high predictor of school success,"p.16. Hester (1989), adding another dimension, made it clear that the home and school relationship must be supported because education is a shared responsibility. Therefore, schools must reach out to parents to establish partnerships because the full potential of children will not be realized unless parents are actively involved. The literature and available research are consistent in showing that meaningful parent involvement results in gainful prospects in student achievement.

The Ministry of Education also placed parental involvement as a high priority level with their platforms. It is quite evident in this slogan from the Ministry of Education which states, "Every child can learn and every child must learn," (Henry-Wilson, 2005). Since $70 \%$ of a student's 
waking hours including weekends and vacations are spent outside the school setting (Clark, 1993), it is imperative that parents are involved in their child's education for success.

Children, in a special way, still need to be guided through assignments and use of study time. As academic and other activities progress through any given scholastic period, the parents' role is to act as vigils, motivators, and guards of what should be their key interestthe holistic development of their young ones.

If schools are going to survive in the 21st century, then educators must begin to give significant attention to building and strengthening the relationship among teachers, parents and principals. Parents can no longer be used as sales agents for tickets, fund-raisers, or called in only when the child is in trouble. Parents need to embrace the education process and be encouraged to play an active role in the day -to day life of the school.

Background of the Problem

It can be said that literacy is the cornerstone of school achievement. Thus, improving school outcomes requires that we focus on raising literacy achievement. "Children may fail to develop adequate reading skills because of their environment, abnormal brain structure, or both," postulates Mark A. Eckert, Ph.D., of the McKnight Brain Institute of the University of Florida.

Poor reading is a major issue that warrants close attention. Educators such as Chall, Jacobs, \& Baldwin, (1990) have noted that boys' reading levels are cause for concern. Boys have been lagging behind girls in reading on the National Assessment Program in our Jamaican schools and this gap seems to be getting wider every year as evidenced in the Grade four literacy results. Boys seem to have a lack of interest when it comes on to reading and as a result of this, it affects them all subject areas.

At Northside All Age School where this research was conducted, there are more boys than girls in most classes. The researcher has seen two grade four classes with 25 boys and 28

girls. They are all given the same opportunity yet the girls seem to be reading and performing above the boys' level. The yearly grade four literacy examinations, which capture the data of students' performance, reveal that boys score ridiculously lower than their counterparts both at the national and regional levels.

\section{Keywords in the Research Process}

The meanings of certain terms used in this are best clarified:

Mastery: the required standard of $80 \%$ in the three areas of literacy to include word recognition, reading comprehension and writing tasks, set by the Ministry of Education for fourth grade level.

Parental involvement: refers to the participation or inclusion of parents or guardians in their children's education by partnership in and contribution to various at home at home.

Parent: is used to refer to mother, step-mother, foster-mother, adopted mother, father, foster father, step- father and adopted father.

Positive parent involvement: refers to the establishment of productive relationships between the school and the home to enhance communication, promote understanding, and provide opportunities for children to interact with people, places and things in their immediate environment and beyond.

Slossons: refers to a standardized reading test used to assess students' reading level from non-starter, to grade nine levels approved by the ministry of education in Jamaica. 


\section{Literature review}

In this chapter the researcher outlined other researchers' views on stimulation on reading and the impact parental involvement have on improving reading.

The prime importance of being able to read has long been recognized: "Reading makes a full person" as mentioned by Beacon, 1596 as stated by Pumfrey (1996) alluded to this and stated, "Reading is also an amplifier of human abilities. Not to be able to read is to be marginalized and impoverished, both culturally and economically" (p. 17). Society recognizes that literacy skills are essential to both the current well-being and the future of the individual and society, and expects that schools should ensure reading standards are safeguarded and raised. Therefore, a teacher should make the teaching of reading a major priority for those reasons.

Concerns about reading standards are not a new phenomenon and these concerns are still with us according to Beard (1993). There is no obvious collective view of what has happened to our national reading standards in recent years but they are decreasing according to Gleaner (2006).

"When parents are involved in their children's education at home, they do better in school. And when parents are involved in school, children are further motivated to the school and the school to which they go progress" (Colker, 2000, p. 3). This quote suggests that it is a wellestablished fact that parental involvement is linked to children's success at school. Epstein(1992) also agreed with statement.

Colker (2000) stated that the positive result of parental involvement in their children's schooling include improved achievement, reduced absenteeism, improved behavior, and restored parental confidence. She further added that the earlier this involvement begins, the more profound the results and the longer lasting the effects. When families are involved in their children's education in positive ways, children achieve higher grades and test scores, complete more homework assignments, demonstrate attitudes and behavior that are more positive, graduate at a higher rate than others, and have greater enrollment in higher education. Parental involvement with older children extends these benefits beyond schooling into later life and career decisions.

Colker (2006) purported that of all academic subjects, reading has been found to be the most sensitive to family influence. In 1994, the College Board established a correlation between reading and family support for their children's effort. Reading achievement is considered to be more dependent on learning activities in the home than is either math or science. Moreover, success in reading appears to be the gateway to success in other academic areas. Lee and Croniger (1994) informed us that children's success in school can be linked to reading to children and listening to them read. Indeed, the single most important activity for building the knowledge required for eventual success in reading is reading aloud to children. In addition, they added that parents can also take their children to the library, help them get a library card, and help them find books on their areas of interest and hobbies. The availability of reading material at the home, whether owned or borrowed from the library, is directly associated with children's achievement in reading comprehension.

It can be said that reading is an essential skill for functioning in society and is fundamental to achievement and success. Yet, an alarming proportion of students have significant difficulties 
with reading. Despite the efforts of teachers, parents and several national educational programs and literacy initiatives over a number of decades (Calfee \& Drum 1986; Steinberg 1996), many students continue to have reading abilities far below those expected at their grade levels. In the Nation's Report Card for Fourth Grade Reading for 2000, more than 68 $\%$ of the nation's fourth graders scored below the recommended proficient level. That number jumps to more than $85 \%$ of fourth graders in high-poverty schools. Poor reading skills adversely affect a student's other learning endeavors, often causing serious learning difficulties and resulting in low academic achievement overall. Consequently, it is imperative to find instructional methods and media to help poor readers develop and improve their reading skills and achieve reading proficiency.

\section{The Importance of Stimulated Activity in Reading}

Snyder \& Tan (2005) postulate that "in our great eagerness to teach our children we studiously look for educational toys, games with built-in lessons and books with a message. Often these tools are less interesting and stimulating than the child's natural curiosity and playfulness". Snyder further states "that play is by its very nature educational, and it should be pleasurable. When the fun goes out of play, most often so does the learning".

Making learning fun motivates students and helps them pay attention and stay focused on the subject. Children will go out of their way to play games, even a single game, for hours, as it captivates their interests.

\section{Effects of Hands on Activity}

According to Wierus and Wierus (1994), Games are designed to exist in relation to a broader array of classroom activities. Games offer teachers enormous resources they can use to make their subject matter come alive for their students, motivating learning, offering rich and compelling problems, and enabling more sophisticated assessment mechanisms. Students are motivated to play games; games make learning fun, so students would not even realize that they are learning. Learning to read is hard work especially when one gets older, it must be maintained over a long period of time. Wierus and Wierus (1994) also stated that games help and encourage many learners to sustain their interest and work.

According to Ersoz (2000), games also help the teacher to create contexts in which reading is useful and meaningful. The learners want to take part and in order to do so must understand what others are reading and they must speak or write in order to express their own point of view or give information.

\section{Boys' Attitudes toward School and Learning}

Several early sociological studies investigated the behavior of specific groups of young men without making 'masculinity' explicit or problematic. These early studies were focused on delinquency and deviance from the 'norm'. In the 1960s and 1970s some researchers were concerned with how socio-economic status affected boys' experiences in secondary schools Hargreaves (1967). These researchers found that working class boys left school earlier and achieved less.

Miller (1998) argues that male and female students perform differently in education because of sex differences in maturation rates and learning styles. While males and females have 
innate differences, influencing factors from children's social environments likely have a more profound impact on their life outcomes than do biological and cognitive differences.

\section{Research Methodology}

The purpose of this research was to ascertain if a literacy garden could be used to improve Grade Four boys' reading level. The sample size included twenty-five boys and twenty eight girls from two Grade Four classes. In this chapter the researcher will outline the type of research and design used to carry out this research.

\section{Research Design}

The researcher undertook a quasi-experiment; this is a type of quantitative research which is used in educational research. Quantitative research, broadly defined, means "any kind of research that produces findings arrived at by means of statistical procedures or other means of quantification" (Strauss and Corbin, 1990, p. 17). Where quantitative researchers seek causal determination, prediction, and generalization of findings, qualitative researchers seek instead illumination, understanding, and extrapolation to similar situations. A quasi experimental design works in natural settings according to Schoenfeld, (2006). The researcher used this design as the class setting would not be interrupted. Shavelson and Towne (2002) cited that with the implementation of No Child Left Behind statue, educational research put forth an agenda of scientifically based research.

The purpose of a quasi-experimental is focused on finding a solution to a problem and the solution can be generalized setting. The purpose of this research was to investigate the impact of a literacy garden on the reading level of grade four boys. Therefore, we addressed the following questions in this study:

1. What was the reading level of fourth grade boys at Northside before treatment intervention?

2. What factors affect the reading level of grade four boys at Northside All Age?

3. How has the implication of Literacy Garden and books from the school library impacted the literacy level of grade four boys?

\section{Method of Data Collection}

\section{Participants}

This 12 - week study was conducted in two $4^{\text {th }}$ grade literacy classes $(\mathrm{N}=53)$ at Northside All Age school with low -socioeconomic background with majority of the parents not completing high school education and are unemployed. Twenty -five boys and twenty -eight girls were tested for reading levels and follow up with parental involvement. They were given a standardized Grade Four Literacy Test. Seventeen boys and sixteen girls were given treatment with the instruction for the literacy garden that was administered by class teacher for twelve weeks before the posttest was given to both the control and the treatment group. The instruments that were used to collect data are, standardized reading test prepared by the Ministry of Education (see Appendix A) with students, academic records that showed progress before and after implementation of strategies. In addition a Slossons test (see Appendix C) was used as a pretest and post test to determine the reading level of the boys. 


\section{Data Collection Instruments}

\section{Slossons}

The Slosson test sheet was distributed to schools by the Ministry of Education for the teacher to ascertain the reading level for the students. A Slosson test is a series of words that range from Primer to High school words for the students to identify (see Appendix C). Each list contains 20 words. The number of words that each students call correctly from each of the word list will be tallied and divided by two for the administrator to know the grade level at which the literacy test as stipulated by the Ministry of Education in word recognition, reading comprehension, and writing. Strategies for literacy garden were implemented and words were planted in garden and students rewarded from books read.

\section{Data Analysis and Results}

Data were analyzed using charts and descriptive statistics to explore the differences among groups. The results showed that there was an increased in literacy performance with pretest and post- test.

\section{Research questions}

This research took the form of a quasi- experimental. The researcher used a sample of 53 students from the Grade 4 class. Thirty-three students in the treatment group to ascertain if the impact of literacy garden could improve their reading level.

This chapter considers the main findings from the data collected using the methods of a pretest and post -test, treatment group when the administration of the group. The following research questions formed the basis of the analysis of the findings.

\section{Research questions}

1. What was the reading level of fourth grade boys at Northside All Age School before the intervention?

2. What factors affect the reading level of Grade 4 boys at Northside All Age?

3. How has the implementation of Literacy Garden and books from the school library impacted the reading level of grade 4 boys?

\section{Research question 1: What are the reading levels of Grade 4 boys at Northside All Age?}

In response to this question the researcher gave a detailed description of the results of the pre- test. The aim of which was to ascertain the reading level of the boys before the administering and implementation of literacy garden.

Students were tested from the levels primer to grade 7 . Each grade level had 20 words. The number of words that each student called correctly from each of the word list was tallied and divided by two to determine the grade level at which the child was reading.

Overall it was noted that majority was reading at their level or slightly above $53 \%$ these students were reading at or above their grade level. The required level of each student is for them to be reading at or above their grade level. I can therefore be said that only some students were reading the required level when the pre-test was administered.

Between September 2014 and December 2014, a pre -test was carried out at Northside All Age School in two grade 4 classes, to be completed by fifty-three students in order to assess pupils' reading levels. Table 1. presents the results for seventeen (17) male pupils 
and sixteen (16) female pupils. The Slossons was used to ascertain these results as recorded below in Table 1.

There were $8(47 \%)$ students reading below or at level three, this was nearly half of the boys' reading at this level. There were five students reading at grade three, which had (5) $29 \%$ reading at this level. The lowest level that the students were reading from was pre-primer which had (1) $6 \%$. There were five (5) at grade four level and four at grade five level.

\begin{tabular}{|l|l|l|}
\hline \multicolumn{3}{|c|}{ Table 1. Reading results from Slossons Treatment Group } \\
\hline GENDER & No of Students & Reading Levels for Sept 2014 \\
\hline M & 2 & Preprimer \\
\hline M & 2 & Grade 1 \\
\hline M & 1 & Grade 2 \\
\hline M & 3 & Grade 3 \\
\hline M & 5 & Grade 4 \\
\hline M & 4 & Grade 5 \\
\hline F & 2 & Grade 2 \\
\hline F & 3 & Grade 3 \\
\hline F & 4 & Grade 4 \\
\hline F & 5 & Grade 5 \\
\hline
\end{tabular}

The table below represents the control group reading results from the Slossons conducted in September, 2014. The results showed that all the male students reading at grade three or below grade three levels.

\begin{tabular}{|l|l|l|}
\hline Table 2. Reading results from Slossons Control Group & \multicolumn{2}{l|}{} \\
\hline Gender & No of Students & Results \\
\hline M & 2 & Grade2 \\
\hline M & 6 & Grade 3 \\
\hline F & 2 & Grade 3 \\
\hline F & 7 & Grade 4 \\
\hline F & 2 & Grade 8 \\
\hline F & 1 & Grade 7 \\
\hline
\end{tabular}

\begin{tabular}{|l|l|l|}
\hline \multicolumn{3}{|l|}{ Table 3. Post Reading Results from Slossons Treatment Group, Dec 2014 } \\
\hline Gender & No of Students & Grade Level \\
\hline M & 1 & Grade 2 \\
\hline M & 1 & Grade 3 \\
\hline M & 5 & Grade 4 \\
\hline M & 2 & Grade 5 \\
\hline M & 3 & Grade 7 \\
\hline F & 1 & Grade 3 \\
\hline F & 6 & Grade 4 \\
\hline F & 3 & Grade 5 \\
\hline F & 3 & Grade 6 \\
\hline F & 3 & Grade 7 \\
\hline
\end{tabular}


Table 3. reflected that was an increased in the reading levels of boys, only two boys were now reading below grade four reading level. There was a seventy-five percent increase in the reading levels of the male students.

\begin{tabular}{|l|l|l|}
\hline \multicolumn{3}{|c|}{ Table 4. Post Reading Results from Slossons Control Group Dec 2014 } \\
\hline Gender & No. of Students & Results \\
\hline M & 2 & Grade 2 \\
\hline M & 5 & Grade 3 \\
\hline M & 1 & Grade 4 \\
\hline F & 2 & Grade 3 \\
\hline F & 7 & Grade 4 \\
\hline F & 2 & Grade 5 \\
\hline F & 1 & Grade 7 \\
\hline
\end{tabular}

Research question 2: What factors affect the reading level of Grade 4 boys at Northside All Age?

The researcher used quasi-experiment research method using treatment of the literacy garden to collect data to respond to this question.

Thirty-three students were given treatment. The researcher used the intact class so as to obtain unbiased outcome at the fourth grade class at Northside All Age.

The information gathered from the treatment group with a semi -structured interview instrument was sorted and was categorized in themes. Based on the information gathered, the themes were used as factors affecting reading level of Grade 4 boys.

\section{The factors affecting reading level of Grade 4 boys}

1. Lack of Parental involvement

2. Demotivation

3. Teaching Strategies

\section{Parental Support}

The students' views were mostly that their parents were not around and they are unable to do homework as they have no help at home as a result of this about six reported that they did not do any school work at home.

Some students felt embarrassed when parents tried to assist them as their parent often used discouraging words while assisting them.

\section{De-motivation}

Students were asked if they liked school. Most reported that school was hard and as a result of that they did not like school. Nine reported that they are often laughed at whenever they said or did something wrong. One student reported that he was bored at school and just did not want to participate in class. Others reported that they could not read well and as a result they just stopped paying attention in class.

\section{Teaching Strategies}

Students were asked what it is that they did not understand when the teacher teaches, some students reported that it was just too fast and they did not understand. Based on what the 
students reported, the students seemed to be having difficulties with the teacher's teaching style. They complained that they liked when games are played in a lesson and when they used objects in the lesson. Therefore these factors are affecting the students both academically and emotionally.

Research question 3: How has the implementation of literacy garden and books from the school library impacted the literacy level of grade 4 boys?

To collect data for research question three, six books from the school library in an effort to these books and planting unfamiliar words in the garden were implemented. The result from the pre-test mock literacy test is depicted in Table 4.5. Literacy Mock Examination was used to answer research question three. The pretest literacy mock examination with treatment group revealed that five male students were at non-mastery level in the examination while two female students were at the near mastery level. Twelve male students gained mastery and fourteen female students mastered.

\begin{tabular}{|l|l|l|}
\hline \multicolumn{3}{|c|}{ Table 5. Results for Pretest Literacy Mock Exam for treatment Group } \\
\hline Gender & No of Students & Results \\
\hline M & 5 & Non Mastery \\
\hline M & 12 & Mastery \\
\hline F & 2 & Near Mastery \\
\hline F & 14 & Mastery \\
\hline
\end{tabular}

Table 6. This table revealed the results from the pretest Literacy Mock from the Control Group. Two male students are at the near mastery and five female students were near mastery level.

\begin{tabular}{|l|l|l|}
\hline \multicolumn{3}{|c|}{ Table 6. Results for Pretest Literacy Mock from Control Group } \\
\hline $\mathrm{M}$ & 2 & Near Mastery \\
\hline $\mathrm{M}$ & 6 & Mastery \\
\hline $\mathrm{F}$ & 5 & Near Mastery \\
\hline $\mathrm{F}$ & 7 & Mastery \\
\hline
\end{tabular}

Table 7. This table revealed the results from the post-test the treatment administered to the treatment group. The treatment had a positive impact on students who sat the posttest. It also revealed that no male student remained at the non- mastery level and three out of the five male students whose scores were deemed at non- mastery now mastered. It therefore can be said that $60 \%$ of the male students soared to mastery while the female students increase was slightly lower.

\begin{tabular}{|l|l|l|}
\hline \multicolumn{3}{|c|}{ Table 7. Results from Post-test for Treatment Group } \\
\hline Gender & No of Students & Results \\
\hline M & 2 & Near Mastery \\
\hline M & 15 & Mastery \\
\hline F & 1 & Near Mastery \\
\hline F & 15 & Mastery \\
\hline
\end{tabular}


Table 8. The table revealed the results from the post-test for the Literacy Mock Examination. It was noted very little change in this group scores.

Table 8. Results from Post-test for Control Group

\begin{tabular}{|l|l|l|}
\hline $\mathrm{M}$ & 2 & Near Mastery \\
\hline $\mathrm{M}$ & 6 & Mastery \\
\hline $\mathrm{F}$ & 5 & Near Mastery \\
\hline $\mathrm{F}$ & 7 & Mastery \\
\hline
\end{tabular}
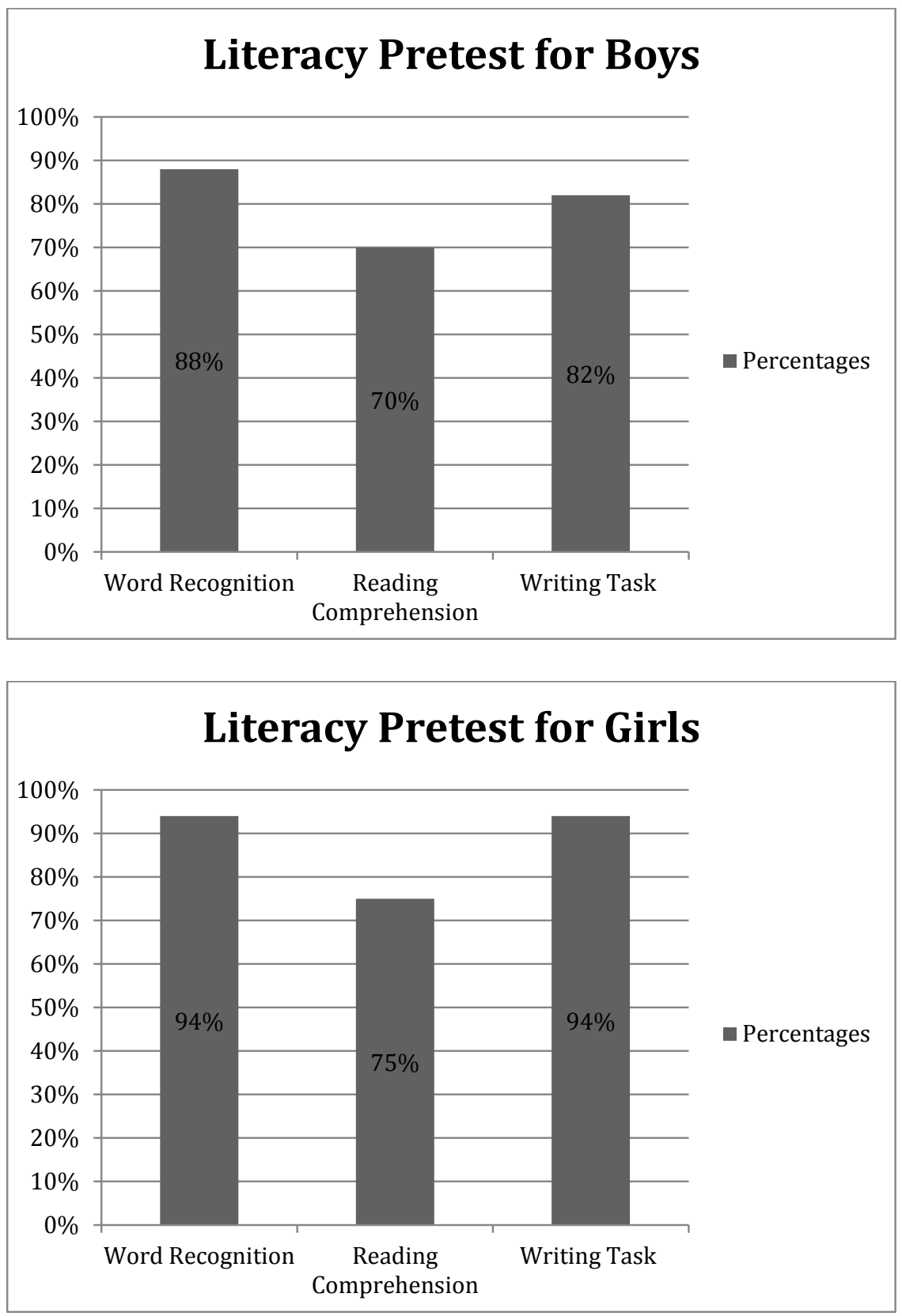
By comparing the pre-test and post -test literacy mock, it is evident that the reading level of all the students had improved. In the pre -test $12(70 \%)$ of the students were doing reading comprehension at mastery level. In comparison to the post test, where $94 \%$ students or sixteen of seventeen boys in the treatment group obtained mastery level in literacy mock test. In the pre-test of the students word recognition was $88 \%$ reading at the mastery level. While the post-test revealed that $17(100 \%)$ of the male students mastered the word recognition. In the pre-test $82 \%$ students mastered the writing task. However after the post test was administered $94 \%$ were mastering writing task. Based on the findings it is evident that there was a marked improvement in the literacy level of the Grade four boys'. All students have improved at least one or more grade levels and $12 \%-24 \%$ on literacy mock post- test. It can therefore be said that there is a significant improvement in the reading levels of the grade four boys after the implementation of the literacy garden and using books from the school library. See Figure 2. below which shows the results from the Post-test.

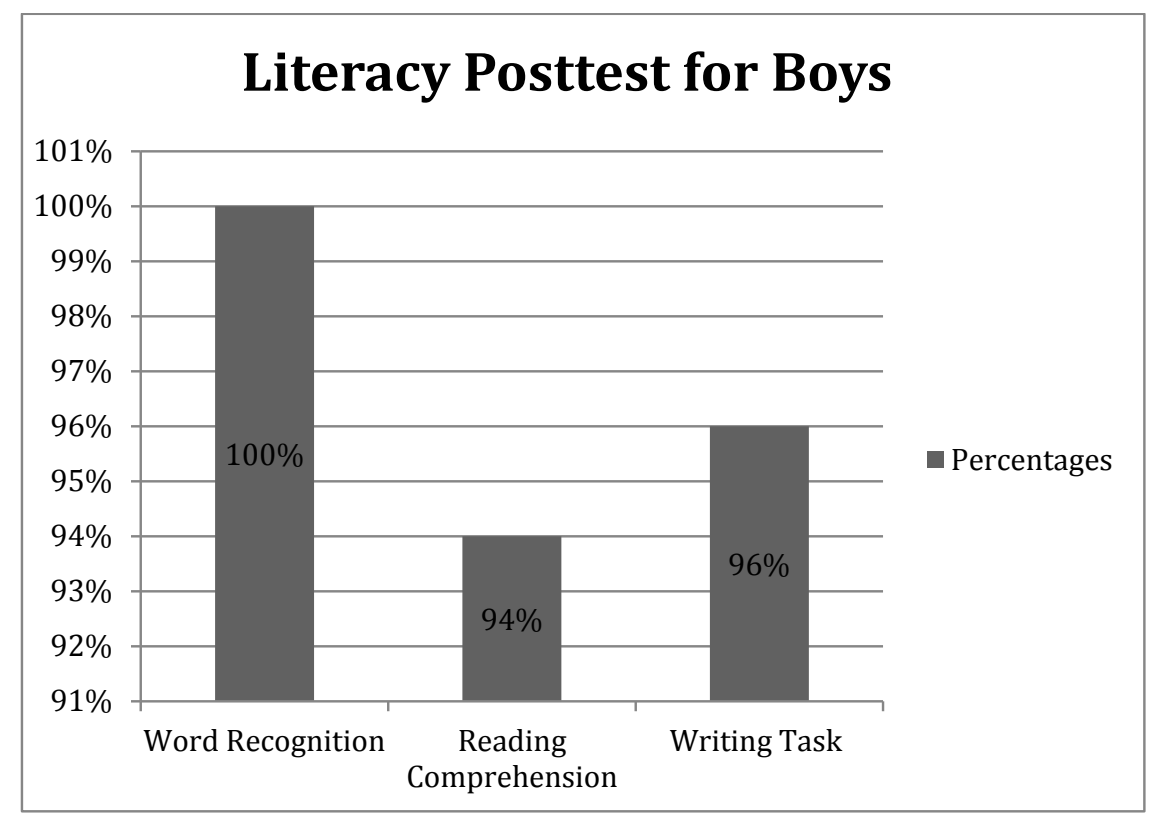




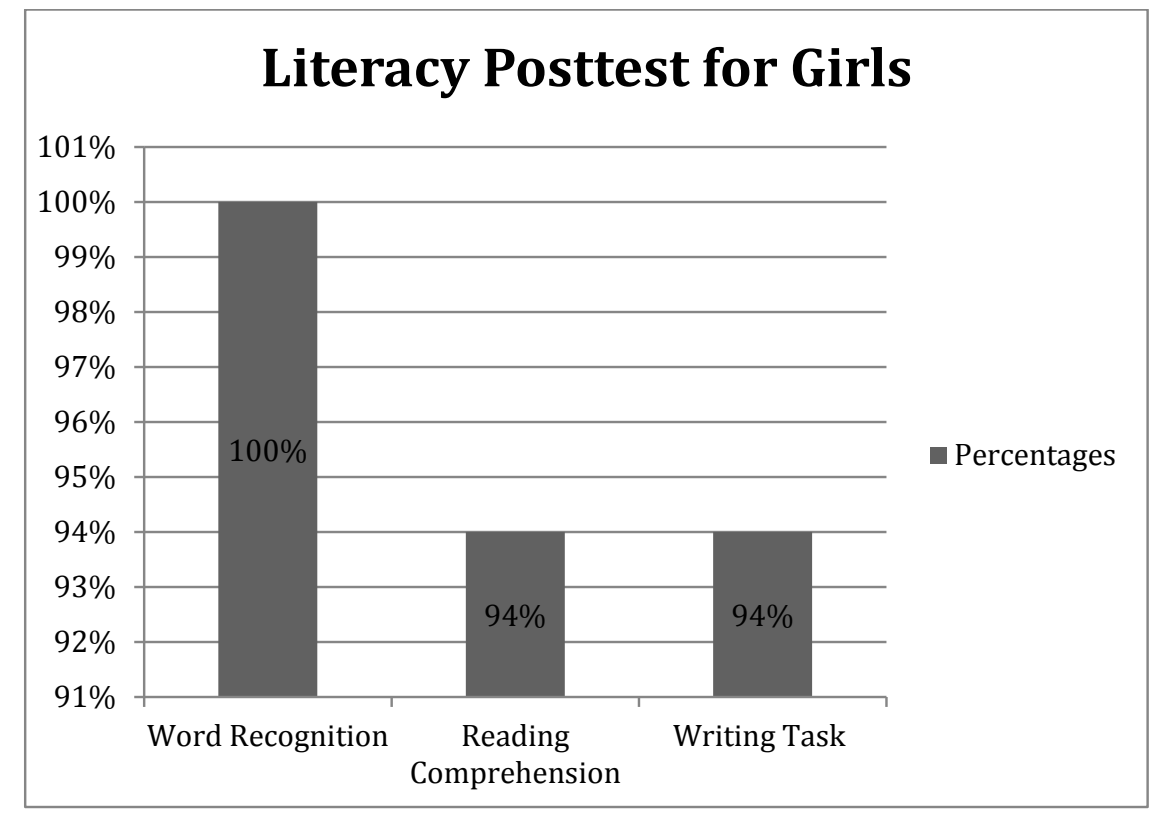

Figure 2.

\section{Summary, Implications and Conclusion}

The researcher conducted quasi experimental research. The sample size of the research was 17 boys and 16 girls from Grade 4 . The purpose of this research was to find out the impact of literacy garden with the use of school library on the reading level of Grade 4 boys. The researcher found from the pre-test that the boys were reading below their grade level. Based on the post test, it was found that planting words in the literacy assisted in improving the boys' reading level. In order for this to happen, six books were implemented to guide the students in improving in their reading. They were challenged to read books from the school library and planting words in the garden. These books got progressively more difficult while they allowed the students to have fun while reading and learning. These books motivated reading habit created by planting words in the literacy garden also addressed different areas in literacy.

The boys all improved at least one or more grade level while $16(96 \%)$ of the boys were reading at the required level for grade four. It found that the factors that affected the boys were Lack of Parental involvement, De-motivation and Teaching Strategy.

According to Miller (2003) reading attainment is positively affected by parental support. The researcher found that parents were not actively involved in their children's school life.

Pearson (1994) postulates that reading is an effortful activity that children often can choose to do or not to do, it also requires motivation. The literature reveals that much of the work relevant to readers' motivation has been framed in terms of attitude towards reading. Reading attitudes typically are defined as readers' affect toward reading (McKenna, 1995). The motivational consequences of reading attitudes are that children with more positive attitudes are more motivated to read. However the researchers' findings were that most of the students felt de-motivated while at school. A substantial body of work also exists on reading interest, defined as either a characteristic of the person or of the text (Schiefele, 1996). Learning strategies are plans which are followed in order to reach learning objectives 
and are techniques that are improved by person to ensure that students understand task when being taught (Derry, 1989).

\section{Conclusion}

Findings from the Slossons and pretest indicated that most the students were reading below their reading level and were not mastering the grade four literacy test. However in comparison with the post test, it was noted that all the students improved at reading level and mastering the grade four mock examinations. Findings from the implementation of the literacy garden and books from the school library were positive. Books that students like to read will keep them involved and eager to learn. The finding could not be generalized because of the sample size but it is noteworthy. The Ministry of Education states that "every child can learn every child must". However not all children learn in the same way and at the same pace. In our society, we have children who are more advanced than others. Some are good readers and others are poor readers. It is our duty as educators to continue to create and implement activities which would foster the academic welfare and growth of these students. This will help the students to become better readers for a brighter tomorrow.

\section{Recommendations}

Based on the overwhelming improvement in the reading level and mastering literacy there are some recommendations that I would like to make. These are based on the three factors that affected reading level and literacy levels in boys. I recommend that:

1. Parents should be more active in their child's/children's school life,

2. Schools should provide regular feedback on pupils' progress and information about ways for parents to support their children's learning.

3. Teachers and parents should find ways to motivate children to read.

4. Teachers should use different teaching strategies with students and know their learning styles so as to address reading issues.

5. Every school should be equipped with a variety of books in the school library that targeted boys and girls.

6. Parents and teachers perceived support and encouragement as major areas of parental involvement and these are important for students' academic achievement.

\section{References}

Calfee, R.C. and Drum, P. 1986. Research on reading instruction. In M. Wittrock (ed.)Handbook Research on Teaching (3rd ed.). New York: Rand McNally

Chall, J. S., Jacobs, V., \& Baldwin, L.(1990). The reading crisis: Why poor children fall behind. Cambridge, MA: Harvard University Press.

Clark, R. (1993). Homework -focused parenting practices that positively affect student achievement. In N.F Chavkin (Ed.). Families and Schools in Pluralistic Society, New York:New : State University of New York Press.

Colker,L. J.(2006) Family involvement: A Key ingredient in children's reading success. Retrieved October 5, 2005, from http://www.rif/parents/articlesFamlnvolvement.mspx 
Derry, S. J. (1989). Putting learning strategies to work. Educational Leadership, 46 (4), 2-7.

Epstein J.L. (1992). School and family partnerships. In M. Alkin (Ed.), Encyclopedia of educational research,(Sixth Edition). New York: MacMillan.

Ersöz, Aydan (2000) Six Games for the EFL/ESL Classroom by The Internet TESL Journal, Vol. VI, No. 6, June.

Fullan, M.2001 Leading in a culture of Change, San Francisco, CA: John Wiley.

Gilmore, T. Krantz, J \& Ramirez, R.(1986). Action Based Modes of Inquiry and the HostResearcher Relationship. Consultation 5.3: 160-76

Hargreaves, D. (1967) Social Relations in a Secondary School. London: Routledge

Hester,H. (1989). Sart at home to improve home school relations. NASSP Bulletin, 73(513), 23-27.

Jesse, D.,(1997). Increasing parental involvement: A key to student academic success.

Lee, V.E. \& Croninger, R.G.(1994).The relative importance of home environment in the development of literacy skills for middle grade students. American of Education. 102 (3). 286-329.

McKenna, M.C., Kear, D.J., \& Ellsworth, R.A. (1995). Children's attitudes toward reading: A national survey. Reading Research Quarterly, 30, 934-955.

Mehrens, W. A. \& Lehmann, I. J. (1987). Using standardized tests in education. New York: Longman.

Miller, E. (2003). The effect of parental involvement (Men at risk). Kingston Jamaica: Jamaica Publishing House

Miller, E. (1998). Education Reform in Independent Jamaica: Themes in Education Reform in the Populist Era. UWI, Mona

Muller, C., \& Kerbow, D. (1993). Parent involvement in the home, school, and community. In B. Schneider, and J.S. Coleman (Eds.), Parents, their children, and schools. Boulder, CO: Westview Press.

National Center for Education Statistics, Institute of Education Sciences, U.S. Department of Education. http://nces.ed.gov/pubsearch/pubsinfo.

Pearson, P.D. (1994). Commentary on California's new English-language arts assessment. Authentic reading assessment: Practices and possibilities (pp. 218-227). Newark, DE: International Reading Association. 
Pumfrey,P. (2006). Reading and writing, Journal of Research in Early Childhood Education, 17(1), 38-40.

Schiefele, U. (1996). Topic interest, text representation, and quality of experience. Contemporary Educational Psychology, 21, 3-18.

Snyder, T.D., \& Tan, A.G. (2005, October). Digest of education statistics, 2004 (NCES publication no. 2006-005). Washington, DC:

Steinberg, Laurence. (1996). Beyond the class-room: Why school reform has failed and what parents need to do. New York: Simon \& Schuster. (ERIC Document No.ED398346)

Strauss, A., \& Corbin, J. (1990). Basics of qualitative research: Grounded theory procedures and techniques. Newbury Park, CA: Sage Publications, Inc.

Wierus, and Wierus. 1994. Zagrag Razem a nami, Cze sc Jezyki abee w szkole, June : 218222.

\section{Biographical note}

Yvonne Perriel is a graduate of Guelph University Ontario, Canada, with a Bachelor of Science Degree in Food Science. She received her Master of Arts Degree in Education from Andrews University in 1998. She earned a Doctor of Philosophy (Ph.D.) in Educational Administration in 2009 from Northern Caribbean University. She is a Master Teacher who has worked in several schools in the Bahamas and Jamaica. She served as an Assistant Professor at Northern Caribbean University for seven years, and now serves as an adjunct professor in Graduate Studies at this institution. Currently, serves as Principal of Goshen All Age, St. Elizabeth, Jamaica.

Dr. Perriel-Mapp has over thirty years working experience in Education.

Among her many awards are: Outstanding Service Award from South Andros, Teacher of the Year for the San Salvador, Bahamas, 2001. Bahamas Union of Teachers- Master Teacher award, 1998. Outstanding Service award in Seventh-day Adventist Service in the Bahamas, Outstanding award 2005 from Teacher Education Department at the Northern Caribbean University, Distinguished Faculty Award from Northern Caribbean University in 2007, Certified Professional in Home Economics in 2011 and Excellence in Teaching from Jamaica Teaching Council in 2014.

Dr. Perriel -Mapp has co-authored one book Introduction to Educational Research. She has presented papers at national, regional and international forums. She also authored four articles in three separate journals.

Dr. Perriel-Mapp's major objectives are to render quality service, to motivate and support others in discovering their hidden potentials, and to empower individuals to make positive changes. She is a motivator, a confidant, but most importantly, she is a Christian lady. 